\title{
Land Use Transitions under Rapid Urbanization: A Perspective from Developing China
}

\author{
Hualou Long ${ }^{1,2, *(\mathbb{D}}$, Xiangbin Kong ${ }^{3}$, Shougeng $\mathrm{Hu}^{4}$ and Yurui $\mathrm{Li}^{2}$ (D) \\ 1 School of Public Administration, Guangxi University, Nanning 530004, China \\ 2 Institute of Geographic Sciences and Natural Resources Research, Chinese Academy of Sciences, \\ Beijing 100101, China; liyr@igsnrr.ac.cn \\ 3 College of Land Science and Technology, China Agricultural University, Beijing 100193, China; \\ kxb@cau.edu.cn \\ 4 Department of Land Resources and Management, China University of Geosciences, Wuhan 430074, China; \\ hushougeng@cug.edu.cn \\ * Correspondence: longhl@igsnrr.ac.cn
}

check for updates

Citation: Long, H.; Kong, X.; Hu, S.; Li, Y. Land Use Transitions under Rapid Urbanization: A Perspective from Developing China. Land 2021, 10, 935. https://doi.org/10.3390/ land10090935

Received: 27 August 2021

Accepted: 1 September 2021

Published: 6 September 2021

Publisher's Note: MDPI stays neutral with regard to jurisdictional claims in published maps and institutional affiliations.

Copyright: (c) 2021 by the authors. Licensee MDPI, Basel, Switzerland. This article is an open access article distributed under the terms and conditions of the Creative Commons Attribution (CC BY) license (https:// creativecommons.org/licenses/by/ $4.0 /)$.

\section{Introduction}

Land use transition is a manifestation of land use and land cover change (LUCC) and is also a major research focus of the Global Land Project (GLP), as well as land system science (LSS). Land provides essential resources to society and its changes have large consequences for the local and global environment and human well-being. The past, current, and projected state and dynamics of land use represent the major focus of land use science, which is influenced by long-term anthropogenic changes. The concept of land use transition highlights the fact that land use change demonstrates a non-linear process and is related to other societal and biophysical disturbances through a series of transitions.

Land use transitions can be seen as primary forces driving the transformation and development of the rural-urban territorial system, and bringing about direct socio-economic and environmental effects on regional sustainability, e.g., resulting in farmland loss and soil degradation, affecting biodiversity and the ability of ecosystems to serve human needs, polluting the rural environment, influencing agricultural production and food security, and causing regional socio-economic and spatial restructuring. Land use transitions can be measured by changes in both the dominant morphology (e.g., quantity, structure, and spatial patterns) and the recessive morphology (e.g., quality, property rights, management mode, fixed input, productive ability, and function) of land use [1,2].

Land use transition is the change in land use morphology, which corresponds to the changes in regional socio-economic development. There is no doubt that rapid socioeconomic development and urbanization processes will inevitably bring about drastic land use transitions. As China is emerging as a global economic superpower with a majority of $64 \%$ of the population representing the urban population, land use transitions during the rapid urbanization in China, with an urban-rural dualism, have received much more attention.

The aim of this Special Issue was to detect or examine the processes, patterns, and socioeconomic and environmental effects of land use transitions in China, the mechanism of human-land interactions against the context of rapid urbanization and industrialization from a wide range of perspectives (i.e., geographical, social-political, ecological, etc.), and the provision of solutions for sustainable land use based on scientific findings.

The collection of peer-reviewed articles in Special Issue number twenty-six includes one review article and twenty-five research articles. The Special Issue is organized in the following way: after the first review paper serving as a background introduction, the following papers are presented under four major topics, such as (a) farmland use management, (b) rural restructuring and vitalization, (c) ecological and environmental effects, and (d) urban development. 
In the review paper [3], the overall picture, development trends, key fields, and hot topics of land use transition research in the past two decades are systematically analyzed from a comprehensive perspective, with the aim to provide scientific support for sustainable land use and environmental management. This review incorporates two complementary parts: the systematic quantitative literature review (based on CiteSpace) and the traditional literature review. The results reveal that there are four key fields and hot topics in land use transition research, i.e., theories and hypotheses of land use transition: i. measuring land use transition; ii. the impacts of land use transition on "social-economic-ecological" systems; iii. drivers and regulation of land use transition. However, challenges remain; current land use transition research is still, to some extent, fragmented, and it should be enriched through an integration with land system science. The dominant morphology bias should be redressed by underlining the recessive morphology transition process. Accordingly, land use transition research needs to be further strengthened in the near future in the following aspects: a. carrying out land use transition research under the guidance of land system science; $b$. attaching importance to the transition of land tenure regimes; c. overcoming the challenges of detecting the recessive morphology of land use; d. linking local land use transition with globalization. Finally, it is clear that the scientific theory on land use transition lags behind the research practice. Despite considerable advances in land use transition research and related fields, an inclusive theory of land use transition or sets of theories has not emerged.

This progress and prospect thinking can be used to help to analyze the issues regarding land use transitions and urban-rural development in China and its eco-environmental effects that arise in the other papers in this Special Issue, which are introduced below under four broad topics.

\section{Farmland Use Management}

There are twelve papers which focus on farmland use transition and land use management in this Special Issue, from the perspectives of dominant morphology, recessive morphology, or both.

Lyu et al. [4] constructed a morphological evaluation index system to identify the characteristics of farmland use transition in the Sihong County of the Huang-Huai-Hai Plain, China. The dominant morphology in terms of area and landscape pattern and the recessive morphology focusing on function were considered in this work. The results show that the implementation of land consolidation projects increased the area and aggregation of farmland, while urbanization and road construction occupied and divided the farmland, leading to a reduction in the area and an increase in the degree of fragmentation. Urbanization increased the demand for agricultural products and the degree of large-scale agricultural production and had a positive impact on the crop production and eco-environmental function of farmland. The research suggested that the government should formulate efficient policies to curb farmland occupation for urban and traffic utilization.

Li et al. [5] and Yang et al. [6] both studied the multiple cropping index, an important recessive morphology of farmland use. Li et al. calculated the multiple cropping index of farmland in China using the S-G filtering method based on the remote sensing data of NDVI, and proposed an optimized regionalization scheme for the use of farmland. The findings reveal that the gap between the multiple cropping index and the potential multiple cropping index of farmland in China is increasingly widening from north to south. Accordingly, four types of areas were classified into key development areas, potential growth areas, moderate development areas, and restricted development areas. Finally, some suggestions such as rotation, fallow, fixed yields with water, and the offset of the balance index with the multiple cropping index were put forward based on different areas. Yang et al. collected MODIS remote sensing image data and land use classification data and conducted a remote sensing inversion on China's multiple cropping index to examine the spatio-temporal changes and factors influencing the multiple cropping index of farmland in China. The results show that natural conditions, the non-agricultural process, the cultivated 
land quality, and agricultural intensification demonstrated different degrees of impact on the multiple cropping index.

Lu et al. [7] explored the green transition of cultivated land use in the Yellow River Basin from the perspective of green utilization efficiency evaluation, which covers the comprehensive benefits of economy, ecology, and society, based on the requirements of ecological civilization and green development construction. The findings reveal that the green utilization efficiency of cultivated land in the Yellow River Basin presents a general distribution characteristic of spatial agglomeration.

Song and Zhang [8] studied the adjustment and optimization of the cultivated land use layout in the typical counties of the main grain production area in Northeast China, based on the planting suitability of the main food crops (rice, soybean, and maize). The findings show that by optimizing the layout of rice, soybean, and maize, the planting suitability level of the food crops and the concentration level of the spatial pattern of cultivated land use layout have been improved. The results may provide a scientific basis and guidance for adjusting the regional planting structure and solving the problem of food structural imbalance.

Zhou et al. [9] investigated the transitional characteristics and triggers of farmland use change through a linear regression analysis, and the internal mechanism of these transitions based on the Advocacy Coalition Framework. The main findings show that macroscopic economic and social changes determined the overall evolution of the farmland area, and there were two advocacy coalitions in the farmland transition policy subsystemthe farmland supplement and farmland consumption coalitions. Under the influence of macroscopic economic and social development, external events play a catalytic role in the transitions, and relatively stable parameters have an indirect but lasting effect in terms of the transition outcomes.

Guo and Wang [10] analyzed the stage characteristics of China's non-grain farming and investigated the spatial agglomeration of non-grain farming and its influencing factors from the perspective of spatial econometrics. The results show that the per capita disposable income of rural residents and the urbanization rate of local areas promoted the development of non-grain farming, while local per capita farmland, road density, and the functional orientation of the main grain-producing areas had a negative impact on non-grain farming. Ultimately, some targeted measures were proposed to promote China's agricultural development in the new era.

Wang et al. [11] studied the relationship between land use transitions and farm performance in China from the perspective of land fragmentation, using detailed household survey data at the crop level from ten provinces in China to construct four land fragmentation indicators and six farm performance indicators. The findings show that land fragmentation increased the input of production materials and labor costs, reduced the purchasing of mechanical services by farmers and the efficiency of ploughing, and may have increased technical efficiency. To improve farm performance, it is recommended that decision-makers speed up land transfer and land consolidation, stabilize land property rights, establish land-transfer intermediary organizations, and promote large-scale production.

Lou et al. [12] analyzed the recessive transition mechanism and the internal differences in arable land use modes of 31 provinces in mainland China by applying an evaluation model to the degree of coupling coordination between the input and output on arable land. The results show that the total amount and the amount per unit area of the input and output on arable land in China have presented different spatio-temporal trends, along with the mismatched movement of the spatial barycenter. The results of this study highlight the different recessive transition patterns of arable land use in different provinces of China, which points to the outlook for higher technical inputs, optimized planting structures, and the coordination of human-land relationships.

Chen et al. [13] investigated the impacts of the farmland transfer-in or transfer-out of different rural households on income structure in Heilongjiang province, the major cereal production area in China, based on the Propensity Score Matching model. The results show 
that the total income of all rural households transferring-in farmland increased significantly, while the income decreased after transferring-out farmland, and part-time households had the largest increase, followed by pure-agricultural households and part-time households. Accordingly, some suggestions were obtained.

Yang et al. [14] explored the characteristics of livelihood capital and the land transfer of farmers under different livelihood strategies and the effect of livelihood capital on land transfer in Sichuan Province. The findings show that pure farmers tended to shift other capital toward natural capital, so their livelihood capital total index value decreased. Parttime farmers had different shift characteristics but their livelihood capital total index value both increased first, and then decreased, and non-farmers tended to shift natural capital towards other livelihood capitals, so their livelihood capital total index value increased. Based on the above analysis, some policy implications were obtained.

Zheng and Zhang [15] analyzed the characteristics of farmers' defaults in different periods and locations based on court decisions regarding rural land mortgage defaults from 2014 to 2020. The empirical results reveal that the time and location of rural land mortgage default cases are widely distributed in China, especially in Heilongjiang Province. It was suggested that when making mortgage loan policies for rural land management rights, financial institutions should give farmers the most preferential treatment regarding the amount, term, and interest rate of loans. Farmers' social security should be improved, and agricultural insurance should be strengthened. Meanwhile, the credit review of small and short-term loan farmers should be heightened.

\section{Rural Restructuring and Vitalization}

Qu et al. [16] constructed a comprehensive research framework of rural residential land scale, structure, and function from the perspective of the combination of the macro and micro scales based on differences between the rural residential areas in the region and the village scale forms. Taking Shandong Province as an example and using model quantitative analysis and horizontal comparative analysis methods, this paper explored the process characteristics of rural residential land use scale transition and the corresponding stage differentiation law of spatial structure and system function. It pointed out that the transition of the rural residential area from the macro to the micro scale is also the process related to the realization of rural restructuring and rural revitalization.

Han et al. [17] proposed a hypothesis of rural-spatial restructuring based on the evaluation of ecological-production-living spaces in terms of the changes in the dominant and recessive morphologies of land use, and analyzed the changes in the dominant morphology of land use by identifying the distribution characteristics of the elements of ecological-production-living spaces and analyzing their structural changes, based on which the process of rural spatial restructuring was judged, and to lay a solid foundation for the next step of rural revitalization. The findings show that combining changes in the ecological-production-living spatial area and quantity as well as changes in functional suitability enables a better understanding of the impact of the national macro-policy shift regarding rural development.

Zhang et al. [18] analyzed the spatio-temporal processes and dilemmas involved in rural industrial land transition by constructing an analytical framework for rural industrial land transition based on spatial governance. The results show that the comprehensive governance of rural space under the analytical framework of "matter-ownership-organization" is an important starting point for analyzing the process of transition of rural industrial land. Rural spatial governance is conducive to promoting the transition of rural land use and the healthy development of rural space. Finally, the authors argued that the experience of semi-urbanized regions with rural revitalization is of vital significance for other regions.

Chai et al. [19] analyzed the changes in both the dominant and recessive morphology of land use in She Village located in the suburban areas of Nanjing by employing participatory rural appraisal, remote sensing, and geographic information systems. The findings show that the She Village witnessed three stages, including industrial development, ecological 
restoration, and service industry development, with more diversified management modes, multifunctional land use, and intensified land fragmentation. This research deepens the understanding of the development process of suburban villages and provides a reference for land policy making and planning in other similar villages.

Tang et al. [20] explored the significant role that village committees play in farmers withdrawal from rural homesteads. The results show that farmers' withdrawal from rural homesteads was significantly affected by the triple roles of village committees, among which an information intermediary was the most effective role, followed by the trust builder, and then the coordinated manager. The authors argued that promising village committees should act as "all-round stewards" in the decision-making of rural households, which not only includes the transmission of information between those above and those below, but also includes the need to actively strive for farmers' trust by letting their voice be heard. Based on the empirical findings, this paper finally proposed some policy suggestions.

\section{Ecological and Environmental Effects}

There are two papers that deal with the ecological and environmental effects of land use transitions in the Loess Plateau of China. Feng and Li [21] established a quantitative evaluation model for establishing the ecological safety effects from the four aspects of dam safety, slope stability, efficient farmland, and effective management, and then scientifically measured the ecological safety effects of land use transitions promoted by land consolidation projects. Three small watersheds (Gutun, Yangjuangou, and Luoping) within the Gully Land Consolidation Project area were employed to verify the evaluation model for the ecological safety effects. The results show that the Gully Land Consolidation Project can effectively improve the ecological environment and promote the development of modern agriculture, but the ecological safety of gullies and slopes in some areas may also face a series of threats due to improper project management measures. Li et al. [22] analyzed land use change and the sense of place of farmers, and further explored the interaction between them in the Yangjuangou catchment of Liqu Town in Baota District, Shaanxi Province. The results indicate that the intensity of the sense of place of local farmers fluctuated downwards, and the decline in the intensity of place attachment and place dependence promoted the reduction in sloping fields, the growth of ecological land, and abandoned fields. This paper suggested that rural areas in the Loess Hilly and Gully Region should strengthen innovation in land use patterns and focus on sustaining farmers' livelihoods in order to promote the harmonious development of human-environmental relations.

Yin et al. [23] analyzed the dynamic patterns of land use transitions in the Yellow River Basin by using the geo-information Tupu method. The results indicate that the Tupu units of the land use transitions were mainly based on the mutual transformation of grassland and unused land, and cultivated land and forestland, which were widely distributed in the upper and middle reaches of the basin. These findings could have theoretical support and policy implications for land use planning and environmental services in the Yellow River Basin.

Chen et al. [24] investigated the habitat quality effect of land use transition and analyzed the cause and mechanism of such changes from an economic-social-ecological complex system perspective in the Henan Water Source area of the Middle Route of the South-to-North Water Transfer Project. The results of this study provided a basis for the improvement of habitat quality, ecosystem protection and restoration, land resource management, and related policies in the Henan Water Source area of the Middle Route of the South-to-North Water Transfer Project.

Pan et al. [25] evaluated the matching degree of water and land resources, and their respective matching degrees with the economic development in the Chengdu-Chongqing Economic Circle with the Gini coefficient method. The results showed that the water and land resources and the economic development of the Chengdu-Chongqing Economic Circle have a high matching degree, but the inner cities have a great difference. The development of the Chengdu-Chongqing Economic Circle needs to promote economic growth and 
technological progress, and at the same time optimize the use of water and land resources to reduce its constraints on economic growth. Finally, policy suggestions of matching water and land resources and economic growth in different regions were put forward.

Cui et al. [26] proposed a new spatially explicit evaluation framework of land use conflict that directly examines three aspects of conflict, namely, ecological and agricultural, agricultural and construction, and ecological and construction land conflicts based on ecological quality and agricultural suitability and evaluated the spatio-temporal dynamic pattern and driving factors of land use conflict in the Yangtze River Economic Belt of China. The findings show that total population, population density, per capita GDP, number of mobile phone users, and road density were strong drivers that influenced the land use conflict of territorial space. Multiple policy recommendations including improving territorial space planning and governance ability, and improving land use efficiency, were proposed to manage and resolve the land use conflict of territorial space.

\section{Urban Development}

Niu et al. [27] constructed a theoretical framework for the interactive relationship between urbanization and land use transition and measured the level of urbanization from the perspective of population urbanization, economic urbanization, and social urbanization, while also evaluating the level of land use morphologies from the perspective of the dominant and recessive morphologies of land use. The results show that the relationship between urbanization and land use transition is not a simple linear relationship but tends to be complex. The process of urbanization, and reasonable urbanization and land use morphologies will promote further benign coupling in the system.

$\mathrm{Li}$ et al. [28] revealed the mechanisms underlying the influence of urban land use transitions on the economic spatial spillovers of central cities to provide a reference for China to optimize the land space layout in cities and to promote their coordinated development. The results show that continuing to strengthen the intensive use of urban land, promoting the improvement of land marketization, and establishing and improving the coordination mechanism for the economic development of urban agglomerations will help to strengthen the economic spatial spillovers of central cities in urban agglomerations.

\section{Concluding Comments}

Research on land use transition has developed rapidly since Long introduced land use transition research into China in 2001 [2]. Undoubtedly, the launch of this special issue of Land including 26 papers accelerates the development of this process to some extent. This special issue has succeeded in compiling theoretical and empirical studies to highlight land use transitions in China. The papers make important conceptual-theoretical and empirical contributions to the growing literature on land use transitions.

The papers in this special issue focus on four major topics, i.e., farmland use management, rural restructuring and vitalization, ecological and environmental effects, and urban development. These topics are also important research themes that need to be strengthened in China during a rapid urbanization process. The recessive morphology concerning the quality, property rights, management mode, input-output, and function of land use obtains the attention it deserves in this special issue. Based on the research results, most papers aim to translate scientific findings on land systems into solutions for sustainable land use, which is what land system science advocates.

However, there is still much more room to improve for land use transition research in China, as far as the papers published in this special issue go. Although some policies have been suggested to tackle the corresponding regional land use or socio-economic development issues, the operationalization of these policies is not without flaws, due to the insufficient attention paid to the interrelations between the urban and the rural and the multi-dimensional driving forces of land use transitions.

On the one hand, China is a nation with strong rural roots. Despite rapid urbanization, nearly half of its population still lives in rural areas. Tremendous land use transitions 
have transformed the development in both rural and urban areas. Accompanying this rapid urban-rural transformation, various land use issues have occurred, giving rise to formulation of new policies directly affecting land use. Therefore, we should bear in mind that the volatility and complexity of land use transitions in China, doomed by the rampant urban-rural transformation and the special 'dual-track' structure of urban-rural development, will present ongoing challenges for further research on land use transitions and urban-rural integrated development, which also needs extensive disciplinary interaction.

On the other hand, the driving forces of land use transitions are not only confined to socio-economic disturbances and physical conditions in one region but are also affected by the displacement effect resulting from international trade [29]. Globalization and urbanization have been two important global trends since the middle of the 20th century. As a result of their interaction, a complex trade network has gradually formed between the urban and the rural as well as between different cities even different countries, thus forming an important tele-coupling context for land use transitions [2]. As such, we need to pay more attention to the distant drivers of land use transitions and link local land use transitions with globalization, which has received much less attention in this special issue.

Author Contributions: Conceptualization, H.L., X.K., S.H. and Y.L.; writing-original draft preparation, H.L.; writing-review and editing, X.K., S.H. and Y.L.; supervision, H.L.; project administration, H.L.; funding acquisition, H.L., X.K. and Y.L. All authors have read and agreed to the published version of the manuscript.

Funding: This research was supported by the National Natural Science Foundation of China (Grant Nos. 41731286, 41971216 and 41971220), and National Social Science Foundation of China (Grant Nos. 19ZDA096 and 21AZD039).

Acknowledgments: We would like to thank all of the contributors to this special issue for their hard work and commitment in producing this volume, and also give our sincere thanks to the editors of Land, for their always present support in this special issue and to the reviewers for their constructive engagement with the manuscripts.

Conflicts of Interest: The authors declare no conflict of interest.

\section{References}

1. Long, H. Land Use Transitions and Rural Restructuring in China; Springer: Berlin/Heidelberg, Germany, $2020 ;$ p. 5.

2. Long, H.; Qu, Y.; Tu, S.; Zhang, Y.; Jiang, Y. Development of land use transitions research in China. J. Geogr. Sci. 2020, 30, 1195-1214. [CrossRef]

3. Long, H.; Zhang, Y.; Ma, L.; Tu, S. Land use transitions: Progress, challenges and prospects. Land 2021, 10, 903. [CrossRef]

4. Lyu, L.; Gao, Z.; Long, H.; Wang, X.; Fan, Y. Farmland use transition in a typical farming area: The case of Sihong County in the Huang-Huai-Hai Plain of China. Land 2021, 10, 347. [CrossRef]

5. Li, T.; Wang, Y.; Liu, C. Research on identification of multiple cropping index of farmland and regional optimization scheme in China based on NDVI data. Land 2021, 10, 861. [CrossRef]

6. Yang, R.; Luo, X.; Xu, Q.; Zhang, X.; Wu, J. Measuring the impact of the multiple cropping index of cultivated land during continuous and rapid rise of urbanization in China: A study from 2000 to 2015. Land 2021, 10, 491. [CrossRef]

7. Lu, X.; Qu, Y.; Sun, P.; Yu, W.; Peng, W. Green transition of cultivated land use in the Yellow River Basin: A perspective of green utilization efficiency evaluation. Land 2020, 9, 475. [CrossRef]

8. Song, G.; Zhang, H. Cultivated land use layout adjustment based on crop planting suitability: A case study of typical counties in Northeast China. Land 2021, 10, 107. [CrossRef]

9. Zhou, X.; Li, X.; Song, W.; Kong, X.; Lu, X. Farmland transitions in China: An advocacy coalition approach. Land 2021, 10, 122. [CrossRef]

10. Guo, Y.; Wang, J. Identifying the determinants of non-grain farming in China and its implications for agricultural development. Land 2021, 10, 902. [CrossRef]

11. Wang, S.; Li, D.; Li, T.; Liu, C. Land use transitions and farm performance in China: A perspective of land fragmentation. Land 2021, 10, 792. [CrossRef]

12. Lou, Y.; Yin, G.; Xin, Y.; Xie, S.; Li, G.; Liu, S.; Wang, X. Recessive transition mechanism of arable land use based on the perspective of coupling coordination of input-output: A case study of 31 provinces in China. Land 2021, 10, 41. [CrossRef]

13. Chen, L.; Chen, H.; Zou, C.; Liu, Y. The impact of farmland transfer on rural households' income structure in the context of household differentiation: A case study of Heilongjiang Province, China. Land 2021, 10, 362. [CrossRef] 
14. Yang, H.; Huang, K.; Deng, X.; Xu, D. Livelihood capital and land transfer of different types of farmers: Evidence from panel data in Sichuan Province, China. Land 2021, 10, 532. [CrossRef]

15. Zheng, H.; Zhang, Z. Analyzing characteristics and implications of the mortgage default of agricultural land management rights in recent China based on 724 court decisions. Land 2021, 10, 729. [CrossRef]

16. Qu, Y.; Dong, X.; Zhan, L.; Si, H.; Ping, Z.; Zhu, W. Scale transition and structure-function synergy differentiation of rural residential land: A dimensionality reduction transmission process from macro to micro scale. Land 2021, 10, 647. [CrossRef]

17. Han, D.; Qiao, J.; Zhu, Q. Rural-spatial restructuring promoted by land-use transitions: A case study of Zhulin Town in Central China. Land 2021, 10, 234. [CrossRef]

18. Zhang, L.; Ge, D.; Sun, P.; Sun, D. The transition mechanism and revitalization path of rural industrial land from a spatial governance perspective: The case of Shunde District, China. Land 2021, 10, 746. [CrossRef]

19. Chai, Y.; Qiao, W.; Hu, Y.; He, T.; Jia, K.; Feng, T.; Wang, Y. Land-use transition of tourist villages in the metropolitan suburbs and its driving forces: A case study of She Village in Nanjing City, China. Land 2021, 10, 168. [CrossRef]

20. Tang, P.; Chen, J.; Gao, J.; Li, M.; Wang, J. What role(s) do village committees play in the withdrawal from rural homesteads? Evidence from Sichuan Province in Western China. Land 2020, 9, 477. [CrossRef]

21. Feng, W.; Li, Y. Measuring the ecological safety effects of land use transitions promoted by land consolidation projects: The case of Yan'an City on the Loess Plateau of China. Land 2021, 10, 783. [CrossRef]

22. Li, Y.; Li, Y.; Fang, B.; Qu, L.; Wang, C.; Li, W. Land use change and farmers' sense of place in typical catchment of the Loess hilly and gully region of China. Land 2021, 10, 810. [CrossRef]

23. Yin, D.; Li, X.; Li, G.; Zhang, J.; Yu, H. Spatio-temporal evolution of land use transition and its eco-environmental effects: A case study of the Yellow River Basin, China. Land 2020, 9, 514. [CrossRef]

24. Chen, M.; Bai, Z.; Wang, Q.; Shi, Z. Habitat quality effect and driving mechanism of land use transitions: A case study of Henan water source area of the middle route of the south-to-north water transfer project. Land 2021, 10, 796. [CrossRef]

25. Pan, Y.; Ma, L.; Tang, H.; Wu, Y.; Yang, Z. Land use transitions under rapid urbanization in Chengdu-Chongqing Region: A perspective of coupling water and land resources. Land 2021, 10, 812. [CrossRef]

26. Cui, J.; Kong, X.; Chen, J.; Sun, J.; Zhu, Y. Spatially explicit evaluation and driving factor identification of land use conflict in Yangtze River Economic Belt. Land 2021, 10, 43. [CrossRef]

27. Niu, B.; Ge, D.; Yan, R.; Ma, Y.; Sun, D.; Lu, M.; Lu, Y. The evolution of the interactive relationship between urbanization and land-use transition: A case study of the Yangtze River Delta. Land 2021, 10, 804. [CrossRef]

28. Li, H.; Chen, K.; Yan, L.; Zhu, Y.; Liao, L.; Chen, Y. Urban land use transitions and the economic spatial spillovers of central cities in China's urban agglomerations. Land 2021, 10, 644. [CrossRef]

29. Meyfroidt, P.; Lambin, E.F.; Erb, K.H.; Hertel, T.W. Globalization of land use: Distant drivers of land change and geographic displacement of land use. Curr. Opin. Environ. Sustain. 2013, 5, 438-444. [CrossRef] 